\title{
ViVan Ratio for Maxillomandibular Tooth Material Discrepancy
}

\author{
Vikrant V. Jadhav ${ }^{1}$, Vasudevan S. D. ${ }^{2}$, Ranjit Kamble³ , Meenakshi M. Tiwari ${ }^{4}$, Neha Bhandari ${ }^{5}$, Sisily Shiji ${ }^{6}$ \\ ${ }^{1}$ Department of Orthodontics and Dentofacial Orthopaedics, SPDC, Sawangi, Wardha, Maharashtra, India. \\ ${ }^{2}$ Department of Orthodontics and Dentofacial Orthopaedics, SPDC, Sawangi, Wardha, Maharashtra, India. \\ 32Department of Orthodontics and Dentofacial Orthopaedics, SPDC, Sawangi, Wardha, Maharashtra, India. \\ ${ }^{4}$ Department of Orthodontics and Dentofacial Orthopaedics, SPDC, Sawangi, Wardha, Maharashtra, India. \\ ${ }^{5}$ Department of Orthodontics and Dentofacial Orthopaedics, SPDC, Sawangi, Wardha, Maharashtra, India. \\ ${ }^{6}$ Department of Orthodontics and Dentofacial Orthopaedics, SPDC, Sawangi, Wardha, India.
}

\section{ABSTRACT}

\section{BACKGROUND}

According to the guidelines of the American and Indian Boards of Orthodontics, it is essential to include second molars, while managing an orthodontic case. Therefore, the present study was planned to determine maxilla-mandibular tooth material discrepancy.

\section{METHODS}

The study sample consisted of study casts of 300 subjects in the age range of 18-30 years. Samples having a full complement of teeth with Angle's Class I molar and canine relationships, good intercuspation, normal overjet and overbite and minimal crowding and spacing were included in the study. Tooth dimensions were measured using digital vernier caliper (accurate to $0.01 \mathrm{~mm}$ ) and overall ratio was calculated. The data was statistically analysed for range, mean, standard deviation and coefficient of variation.

\section{RESULTS}

ViVan ratio was found to be 90.79 with standard deviation of 3.13, variance of 9.81 and range was 83.55 - 95.82 .

\section{CONCLUSIONS}

Ideal tooth proportions play an important role in achieving good occlusion at the end of orthodontic treatment. The ViVan ratio obtained in the study included second molars and this would benefit the orthodontist in proper treatment planning. This ratio will add importance for improved results at the finish of orthodontic treatment.

\section{KEY WORDS}

Bolton's Ratio, Second Molar, Mesiodistal Width, Digital Caliper and $7^{\text {th }}$ Key
Corresponding Author: Dr. Vikrant V. Jadhav, $3^{\text {rd }}$ Year Junior Resident, Department of Orthodontics and Dentofacial Orthopaedics, SPDC, Sawangi, Wardha, Maharashtra, India.

E-mail: vikrantjadhav9405@gmail.com

DOI: $10.14260 / \mathrm{jemds} / 2020 / 406$

Financial or Other Competing Interests: Dr. Jadhav has a patent copyright licensed.

How to Cite This Article: Jadhav VV, Vasudevan SD, Kamble R, et al. ViVan ratio for maxillomandibular tooth material discrepancy. J. Evolution Med. Dent. Sci. 2020;9(25):1865-1868, DOI: $10.14260 /$ jemds/2020/406

Submission 13-01-2020,

Peer Review 23-05-2020,

Acceptance 29-05-2020,

Published 22-06-2020.

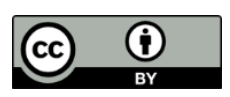




\section{BACKGROUND}

Aim of orthodontic treatment is good occlusion with perfect over jet and overbite. An inter-maxillary tooth size disproportion is the important features that is for achieving an acceptable orthodontic treatment outcome. A tooth size discrepancy is a disparity between the sizes of individual teeth. There are different phases in orthodontic treatment, among them one of the phases is "finishing phase" which is not only important but also very difficult phase. It is so because tooth size disproportion which has to be detected and considered during initial diagnosis and treatment planning. Orthodontics must be acquainted with all these disproportion in tooth size at the initial phase of diagnosis and treatment planning to achieve brilliance in orthodontic finishing.

In order to achieve perfection in orthodontic finishing, Orthodontics must know discrepancies in tooth size from the point of initial diagnosis to the making of treatment plan. To know tooth size discrepancies plays an important aspect majorly in the anterior segment of jaw. An acceptable occlusion governs by a correct ratio between the dental masses in the maxillary and mandibular arches.

Many studies suggest with marked evidence that there is difference in the populations if compared with interarch tooth size relationships because disproportion in tooth sizes are not in order which may be due to the population and gender differences in maxillary tooth size which are not same as the differences in mandibular tooth size, different interarch relationships might be anticipated. Studies on the relationship between tooth size discrepancy and different group of malocclusions has also been done. Many studies suggested that when ratio of tooth discrepancy was taken in Class III, Class II and Class I, it was found greater in class III malocclusion as compared to Class I and Class II which lead to the conclusion that the Bolton analysis must be considered during diagnosis and treatment planning. Some studies have also been done by keeping normal occlusion in mind to find out the trend in tooth size discrepancy in patients with normal occlusion and compared it with the Bolton and found out there was no significant differences in two studies.

Patients seeking treatment for aesthetic reasons in all the branches of dentistry have increased. Establishment of good occlusal scheme is an important goal of orthodontic therapy. To achieve this objective, teeth of the maxillary and mandibular arches should be proportional. This proportionality is referred to a $7^{\text {th }}$ key occlusion.

Profitt in 2007 defined Tooth Size Discrepancy (TSD) as a disproportion among the size of individual teeth. Acceptable occlusion is necessary to achieve an ideal overjet and overbite. For this, perfect tooth size harmony should be evaluated.(1)

Formula proposed by Bolton(2) included two ratios i.e. anterior ratio and overall ratio. Mesiodistal widths of the anterior teeth of both arch represented anterior ratio and the total width represented overall ratio. This ratio was formulated in Caucasian (female) population. Therefore, its applicability was also questioned by many authors(3-7) in Indian population due to genetic predisposition.

According to the guidelines by the American and Indian boards of Orthodontics, it is essential to include second molars, while managing an orthodontic case. But, there are no formulae to estimate the proportionality which include the second molars. ${ }^{(8)}$

\section{METHODS}

The present study was carried out at after the approval from the Institutional Ethical committee. For the study, the potential participants were examined clinically. The following inclusion and exclusion criteria were used to select the participants.

\section{Inclusion Criteria}

- Fully erupted dentition up to second permanent molar with no interproximal caries, restorations, attrition, and dental anomaly.

- No previous or ongoing orthodontic treatment.

\section{Exclusion Criteria}

- Carious teeth.

- Altered number or shape of the teeth.

- History of Orthodontic treatment.

Informed consent was obtained from those participants who meet the inclusion criteria. A total of 300 participants was included. Following this, accurate impression of upper and lower dental arches was recorded using putty impression material. The impression was poured immediately with dental stone (Kaldent Dental Plaster Class III) to minimize distortion of impression. The cast were retrieved after the dental stone was set and bases were poured, and measurement were carried out on the casts. This is an observational study.

\section{Methods}

A modified digital vernier caliper will be used to measure the mesiodistal width of the teeth. The tips of the caliper will be modified to fit into the contact points of the teeth. The tips of the caliper will be placed in the contact point of the tooth and the mesiodistal width of the teeth will be recorded and entered into the chart shown below. (Figure no. 1) (Table no. 1)

\section{ViVan Ratio / Overall Ratio}

$$
\frac{\text { Sum mandibular } 14}{\text { Sum maxillary } 14} \times 100=90.79
$$

The mesiodistal widths of fourteen maxillary teeth, the right second permanent molar through the left second permanent molar, will be totaled and compared to the sum derived from the same procedure carried out on the fourteen mandibular teeth. The ratio between the two is the percentage relationship of mandibular arch length with maxillary arch length which we have called the "ViVan ratio." 


\section{RESULTS}

\section{Overall Ratio}

$$
\frac{\text { Sum mandibular } 14}{\text { Sum maxillary } 14} \times 100=90.79
$$

The sum of mesiodistal width of mandibular teeth from second molar of right side till second molar of left side was calculated. Then sum of mesiodistal width of maxillary teeth from second molar of right side till second molar of left side was done. Further the calculated mesiodistal width of mandibular teeth was divided by maxillary teeth. Percentage was obtained by multiplying the resultant by 100 .

Table 2: gives the descriptive statistics including the mean, standard deviation, variance and range of the 7:7 ratios for the participants.

Following results were obtained: mean value for overall ratio was 90.79 , Standard deviation was 3.13 , Variance of 9.81 and range of 83.55-95.82. The mean AR in our study was found out to be $90.79 \pm 3.13$.

\begin{tabular}{|cccccccccccccccc|}
\hline UR & 17 & 16 & 15 & 14 & 13 & 12 & 11 & 21 & 22 & 23 & 24 & 25 & 26 & 27 & UL \\
LR & 47 & 46 & 45 & 44 & 43 & 42 & 41 & 31 & 32 & 33 & 34 & 35 & 36 & 37 & LL \\
\hline \multicolumn{1}{|c|}{ Table 1. Chart for Recording of Mesiodistal Width of Teeth } & \\
\hline
\end{tabular}

\begin{tabular}{|c|c|c|c|c|c|}
\hline 7.7 & $\mathbf{N}$ & Mean & Std. Deviation & Variance & Range \\
\hline $1 / 7$ & 300 & 90.7974 & 3.13328 & 9.817 & $83.55-95.82$ \\
\hline
\end{tabular}

\section{DISCUSSION}

Ideal overbite and overjet are attained with comprehensive orthodontic treatment. Tooth size arch length discrepancy is the major factors that jeopardize a good orthodontic treatment outcome. A tooth size arch length discrepancy is a disproportion among the dimensions of individual teeth. There are various stages of orthodontic treatment. Out of this "finishing stage" is believed to be very tough because of tooth size disproportions that could have been addressed and giving preference during preliminary diagnosis and treatment planning stage. The clinician must be acquainted with such disproportions in tooth size at the preliminary diagnosis and treatment planning stages if good orthodontic finishing is to be attained.

Ideal tooth ratio plays a significant part in attaining acceptable occlusion at the finish of orthodontic treatment. Tooth size ratio should be given prior preference during treatment planning. Aesthetic harmony, structural balance and functional efficiency should be goal of an orthodontist. Structural balance is achieved by achieving proper tooth size arch length discrepancy. During treatment planning all these aspects should be kept in mind. Failure to achieve these fundamentals will result in compromised outcome. A balance should be attained between these factors.

Proper tooth size determination i.e. essential for acceptable intercuspation of teeth. In individuals with normal occlusion the proportion of teeth between the maxillary and mandibular is maintained. However, this alternation in the proportion of the teeth and improper intercuspation causing malocclusion.

The term tooth size refers to the mesiodistal width of the teeth. G. V. Black in 1902 investigated to tooth size.(1)

In 1958, Wayne Bolton(2) gave a new numerical ratio to specify that mandibular twelve teeth were 91.3 of maxillary twelve teeth and mandibular six anterior teeth were 77.2 of maxillary six anterior teeth. These two formulae and ratios were established on Caucasian population. Their ratio when applied to normal occlusion gave inaccurate results.

Bennett and McLaughlin(8) added a seventh key "tooth size". A tooth size discrepancy is a discrepancy between the dimensions of individual teeth, which will ultimately affect fulfilment of an ideal occlusion. Many authors (3-7) proposed an intermaxillary ratio analysis designed for the purpose of localizing discrepancies in tooth size for Indian population. Lundstrom(7) reviewed the European literature that dealt with tooth disharmonies and concluded that there was genetic predisposition in the measurements of mesiodistal width of tooth size and hence could not be applied to all populations.

Ideal tooth proportions play an important role in achieving good occlusion at the end of orthodontic treatment. Ideal tooth proportion was studied and reported by Bolton in 1958. Original Bolton's analysis included ratio till First molar. Proper alignment of the second molars is the necessary during orthodontic treatment. According to the ABO guidelines, at the end of orthodontic treatment all the teeth should be aligned especially permanent second molars should be fully erupted and aligned.

Alignment of second molars of both maxillary and mandibular arch is important. Failure to do so may lead problems in all three dimensions. Problems encountered are improper proximal contact, occlusal disharmony and malalignment. Also, during retraction exclusion of permanent second molar may lead to a greater anchorage loss in both labial as well as lingual orthodontics.(9-11)

According to Lundstrom tooth size ratio between anterior teeth of maxillary and mandibular arches are of utmost importance. Study conducted by Neff presented that the ratio of teeth size related to overbite mathematically which also responsible for determination of coefficient of the teeth. (7) These ratio were determined in Caucasian population and had involved ratios of 12 maxillary and mandibular teeth. Gilpatric found out that in maxillary teeth sum of the mesiodistal widths surpasses the mandibular teeth by $8-12$ $\mathrm{mm}$, and are directly proportional i.e. greater the value, overbite will also be greater.(12) Bolton (2) presented the study where he compared the sums of mesiodistal width of maxillary and mandibular tooth followed by determination of ideal tooth size ratio between the mesiodistal width of overall and the anterior teeth. This analysis has an impact on examination followed by diagnosis and treatment planning of orthodontic patient which is still followed today even in the era where advancement taking place in every day. Among the many analysis which has been done, Bolton's analysis of overall and anterior teeth is commonly used in both clinical and scientific studies when evaluating the discrepancy between mesiodistal width of maxillary and mandibular arch. This ratio was derived in Caucasian population and till maxillary and mandibular first molar. It was proven by many studies that this ratio is affected by genetic predisposition, 
still every clinician was following this. According to $\mathrm{ABO}$ guidelines it was mandatory to align second molars in occlusion. Seconds along with first molar provide good occlusal table for mastication. Therefore, ViVan ratio provides this ratio and this ratio should be used to achieve acceptable occlusion.

Recently, researches have carried out evaluation of the relationship between the discrepancy of mesiodistal tooth size of maxillary and mandibular arch including Angle's Class I, II, and III malocclusions, overjet, and overbite but literature suggest that results were contradictory. Study done by Akyalcin(13) evaluated the relationship between the Bolton ratio and overjet, where he found out that relationship between the Bolton overall ratio and the size of over jet was statistically significant. The studies where relationship between Angle Class I, II, and III malocclusions and the Bolton ratio are evaluated are found to be contradictory. Many studies were unsuccessful to find any statistically significant difference between relationship of the value of the Bolton ratio and the first permanent molars on the basis of Angle's classification of malocclusion. This study also lacked such characteristic. Other features of Angle's malocclusion should have been covered. Only Angle's class I malocclusion cases are covered.(14-18)

Gender preferences are lacking in the study.

\section{CONCLUSIONS}

Second molar has gained importance due to early loss of first molars. Either first molars are carious, or they are missing. Therefore, permanent second molar tooth plays an important role in maintaining normal masticatory function and dentofacial harmony. It is therefore important to include second molars in orthodontic treatment. Hence, there was a need to derive ViVan ratio for our population.

\section{REFERENCES}

[1] Santoro M, Ayoub ME, Pardi VA, et al. Mesiodistal crown dimensions and tooth size discrepancy of the permanent dentition of Dominican Americans. Angle Orthod 2000;70(4):303-7.

[2] Bolton WA. Disharmony in tooth size and its relation to the analysis and treatment of malocclusion. Angle Orthod 1958;28(3):113-30.

[3] Jindal R, Bunger E. Bolton's intermaxillary tooth size ratios among school going children in Punjab population. Indian Journal of Oral Sciences 2013;4(3):110.

[4] Subbarao VV, Regalla RR, Santi V, et al. Interarch tooth size relationship of Indian population: does Bolton's analysis apply? J Contemp Dent Pract 2014;15(1):103-7.
[5] Saritha T, Sunitha C, Kumar PK, et al. Applicability of Bolton's analysis to a South Telangana population. Indian J Dent Sci 2017;9(4):225-32.

[6] Patel YV, Nair VS, Jamenis SC. Bolton analysis of the Maratha population in Pune. J Dent Allied Sci 2017;6(1):8-11.

[7] Lundstrom A. Intermaxillary tooth width ratio and tooth alignment and occlusion. Acta Odontol Scand 1955;12(34):265-92.

[8] Bennett JC, McLaughlin RP, John BC. Orthodontic treatment mechanics and the pre-adjusted appliance. London: Wolfe Medical Publishing 1993.

[9] Thote AM, Uddanwadiker RV, Sharma K, et al. Optimum en-masse retraction of six maxillary anterior teeth in lingual orthodontics: a numerical investigation with 3dimensional finite element analysis. Molecular and Cellular Biomechanics 2017;14(1):1-17.

[10] Thote AM, Sharma K, Uddanwadiker RV, et al. Optimum pure intrusion of a mandibular canine with the segmented arch in lingual orthodontics. Biomed Mater Eng 2017;28(3):247-56.

[11] Thote AM, Uddanwadiker RV, Sharma K, et al. Optimum force system for intrusion and extrusion of maxillary central incisor in labial and lingual orthodontics. Computers in Biology and Medicine 2016;69:112-9.

[12] Freeman JE, Maskeroni AJ, Lorton L. Frequency of Bolton tooth-size discrepancies among orthodontic patients. Am J Orthod Dentofacial Orthop 1996;110(1):24-7.

[13] Lopatiene K, Dumbravaite A. Relationship between tooth size discrepancies and malocclusion. Stomatologija 2009;11(4):119-24.

[14] Tiwari MM, Jadhav VV, Kamble RH, et al. A review on evolution and controversies regarding surgical methods and timing of palatoplasty in UCLP cases. J Evolution Med Dent Sci 2020;9(4):236-45.

[15] Ghoshal PK, Kamble RH, Shrivastav SS, et al. Radiographic evaluation of alveolar bone dimensions in the inter radicular area between maxillary central incisors as "safe zone" for the placement of mini-screw implants in different growth patterns--a digital volume tomographical study. J Evolution Med Dent Sci 2019;8(51):3836-40.

[16] Jadhav VV, Vasudevan SD, Kamble R, et al. Comparison of Bolton's ratio for evaluation of tooth size discrepancy between maxillary and mandibular arches in Vidarbha population. J Evolution Med Dent Sci 2020;9(21):165962.

[17] Tiwari MM, Daigavane PS, Kamble R, et al. Establishment of cephalometric norms for UCLP cases from central india population falling under goslon 1 and 2 based on burstone analysis. J Evolution Med Dent Sci 2020;9(16):1365-8.

[18] Jadhav VV, Vasudevan SD, Kamble R, et al. ViVan Formula- a modified formula for estimating the mesiodistal width of maxillary central and lateral incisor. J Evolution Med Dent Sci 2020;9(14):1144-7. 